\title{
Solubility of Sodium Acetate in Ternary Mixtures of Methanol, 1-Propanol, Acetonitrile, and Water at $298.2 \mathrm{~K}$
}

\author{
Jafar Soleymani, ${ }^{\dagger}$ Ernst Kenndler, ${ }^{\ddagger}$ William E. Acree, Jr., ${ }^{\S}$ and Abolghasem Jouyban*,ll, \\ ${ }^{\dagger}$ Tuberculosis and Lung Disease Research Center and "Drug Applied Research Center and Faculty of Pharmacy, Tabriz University of \\ Medical Sciences, Tabriz, Iran \\ ${ }^{\ddagger}$ Institute for Analytical Chemistry, Faculty of Chemistry, University of Vienna, Währingerstrasse 38, A 1090 Vienna, Austria \\ ${ }^{\S}$ Department of Chemistry, University of North Texas, Denton, Texas 76203-5070, United States \\ ${ }^{\perp}$ Pharmaceutical Engineering Laboratory, School of Chemical Engineering, College of Engineering, University of Tehran, P.O. Box \\ 11155/4563, Tehran, Iran
}

\begin{abstract}
The solubility of sodium acetate in ternary solvent mixtures of water + methanol $(\mathrm{MeOH})+$ acetonitrile $(\mathrm{ACN})$, water $+\mathrm{MeOH}+1$-propanol $(\mathrm{PrOH})$, water $+\mathrm{PrOH}+\mathrm{ACN}$, and $\mathrm{MeOH}+\mathrm{PrOH}+\mathrm{ACN}$ at $298.2 \mathrm{~K}$ is reported and mathematically represented using two numerical analyses (based on measured solubility data in 54 ternary mixtures containing the particular solvents in the mass fraction ranges between 0.08 and 0.84 ). In the first analysis, the solubility is predicted using the Jouyban-Acree model constants for the binary mixtures of the respective solvent pairs that were used to prepare the ternary mixtures. By this approach, the overall mean percentage deviation (OMPD) of the predicted data in ternary solvents is $57 \%$. The largest OMPD for this model was up to $80 \%$ for a mixture of water, $\mathrm{PrOH}$, and ACN. To improve the model, an additional term (with ternary constants $J_{i}^{\|}$) was included, reflecting the combined effect of all three solvents in a mixture. By this numerical

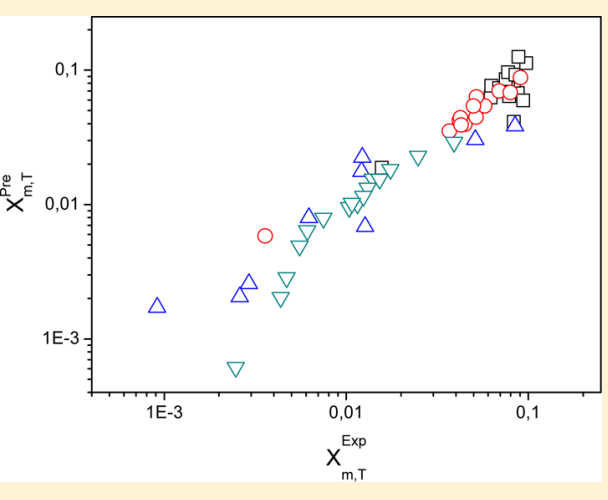
analysis, the experimental ternary solubility data is used to calculate the additional ternary constants. After employing the calculated constants, the prediction of the solubility in the ternary mixtures was improved significantly by a factor of 2 with an OMPD of $25 \%$. As an additional ability of the Jouyban-Acree model, the density of the solute saturated solutions in the solvent mixtures is predicted using three numerical methods; i.e., (i) data of solute saturated solutions in the binary solvent mixtures, (ii) ternary mixtures, and (iii) density data of solute free binary solvent mixtures with predicting errors (OMPD) of $1.2 \%, 3.0 \%$, and $2.8 \%$, respectively.
\end{abstract}

\section{INTRODUCTION}

It is important to know the solubility of salts in organic and mixed solvent systems in many industrial and natural processes such as solubilization, crystallization, liquid extraction, distillation, and inorganic salt absorption. The solubility of electrolytes in nonaqueous solvents is essential for theoretical studies concerning the liquid phase structure and its thermodynamic properties. Also, the solubility of inorganic salts plays a significant role in determining the physical and chemical properties of ionic solutions. However, such solubility phenomena are less studied and often very scarce. Sometimes the published data measured by different researchers are even contradictory. ${ }^{1,2}$

Sodium acetate is an important material in many fields of science and technology. In food industries, it is used as a buffer constituent in controlling the $\mathrm{pH}$ during various stages of processing and is used as a seasoning. It is one of the FDA recommended materials as a food additive. ${ }^{3}$ In petroleum and textile industries, ${ }^{4}$ it is used as a buffering agent and for the neutralization of sulfuric acid waste streams, respectively. In medical applications, it is used as a fluid bath for hemodialysis ${ }^{5}$ and as a source of sodium for addition to large volume intravenous fluids to prevent or correct hyponatremic patients. ${ }^{6}$ The rubber industries, tanning, concrete, and heating pads are other application areas involving sodium acetate (or other features). ${ }^{4}$ In analytical sciences, sodium acetate is an important buffering constituent in high-performance liquid chromatography (HPLC) and capillary electrophoresis (CE) systems. ${ }^{7}$

Because of the importance of sodium acetate in the areas mentioned above, we found it worth reporting the solubility data of this salt in ternary solvent mixtures of water $+\mathrm{MeOH}+$ $\mathrm{PrOH}$, water $+\mathrm{MeOH}+\mathrm{ACN}$, water $+\mathrm{PrOH}+\mathrm{ACN}$, and $\mathrm{MeOH}+\mathrm{PrOH}+\mathrm{ACN}$ at $298 \mathrm{~K}$ and to apply the JouybanAcree model for correlation and/or prediction of the measured data.

Over the past few decades, several models have been developed to predict the solubility of salts and nonionic materials. The previously used electrolyte activity coefficient based models such as the Pitzer's model, e-Wilson model, eNRTL model, UNIQUAC, and LIQUAC models were used for

Received: June 2, 2014

Accepted: July 16, 2014

Published: August 4, 2014 
modeling phase equilibria, thermodynamic properties, and solubility of electrolytes in nonaqueous solutions. ${ }^{1,2}$ However, these models are often complex and contain many parameters; moreover, their calculation can be very complex and timeconsuming.

The Jouyban-Acree model has been used for the solubility prediction of drug candidates in ionized and nonionized forms, but with the exception of our previously published paper, ${ }^{7}$ no attempt has been made to employ this model for the prediction of inorganic salts. The favorable results in binary solvent mixtures encouraged us to apply and evaluate this model for ternary mixtures as well. Whereas activity based models often need numerous experimental data for solubility (activity coefficient) prediction, the Jouyban-Acree model only needs the solubility in the monosolvents at the given temperature of interest after training by a minimum number of experimental data points in mixed solvents. This model provides more accurate mathematical descriptions and shows how the solute solubility varies with both temperature and solvent composition. The general form of this model for solute solubility in binary solvent mixtures is ${ }^{8}$

$$
\ln C_{m, T}^{\mathrm{Sat}}=w_{1} \ln C_{1, T}^{\mathrm{Sat}}+w_{2} \ln C_{2, T}^{\mathrm{Sat}}+\frac{w_{1} w_{2}}{T} \sum_{i=0}^{2} J_{i}\left(w_{1}-w_{2}\right)^{i}
$$

where $C_{m, T}^{\text {Sat }}, C_{1, T}^{\text {Sat }}$, and $C_{2, T}^{\text {Sat }}$ are the molar solubilities of the solute in the mixed solvents, and in the monosolvents 1 and 2 , respectively, at temperature $T . w_{1}$ and $w_{2}$ denote the mass fractions of solvents 1 and 2 , and model constants $J_{\mathrm{i}}$ represent the (two-body) solvent-solvent and (three-body) solventsolute interactions of the solutions. ${ }^{9}$ Concerning the derivation of eq $1,{ }^{10}$ the model constants are not temperature-dependent, and the effects of temperature on the solubility are presented by the $T$ term in the equation. The $J_{\mathrm{i}}$ values can be calculated using a no-intercept least-squares regression analysis of $\left(\ln C_{m, T}^{\text {Sat }}-w_{1}\right.$ $\left.\ln C_{1, T}^{\text {Sat }}-w_{2} \ln C_{2, T}^{\text {Sat }}\right)$ against $\left(w_{1} w_{2}\right) / T,\left[w_{1} w_{2}\left(w_{1}-w_{2}\right)\right] / T$, and $\left[\left(w_{1} w_{2}\left(w_{1}-w_{2}\right)^{2}\right] / T\right.$. Equation 1 is derived from the combined nearly ideal binary solvent/Redlich-Kister equation by addition of temperature as an additional independent variable. Some theoretical justifications could be found from previous works; ${ }^{9-12}$ however, we prefer to use the model as a semiempirical model.

The model could also be used to compute the solute solubility in ternary solvent mixtures as ${ }^{8}$

$$
\begin{aligned}
& \ln C_{m, T}^{\text {Sat }}=w_{1} \ln C_{1, T}^{\text {Sat }}+w_{2} \ln C_{2, T}^{\text {Sat }}+w_{3} \ln C_{3, T}^{\text {Sat }} \\
& +\left[\frac{w_{1} w_{2}}{T} \sum_{i=0}^{2} J_{i}\left(w_{1}-w_{2}\right)^{i}\right]+\left[\frac{w_{1} w_{3}}{T} \sum_{i=0}^{2} J_{i}^{\prime}\left(w_{1}-w_{3}\right)^{i}\right] \\
& +\left[\frac{w_{2} w_{3}}{T} \sum_{i=0}^{2} J_{i}^{\prime \prime}\left(w_{2}-w_{3}\right)^{i}\right]
\end{aligned}
$$

in which $C_{3, T}^{\text {Sat }}$ and $w_{3}$ are the solubility of the solute in monosolvent 3 and its mass fraction, respectively. The constants $J_{i}$ in eq 2 could be calculated by using the abovementioned method. Equation 2 does not need additional solubility data in ternary solvent mixtures in its training process; however, it may lead to higher error values.

To provide more accurate predictions, additional ternary interaction terms can be implemented in eq 2 as

$$
\begin{aligned}
& \ln C_{m, T}^{\text {Sat }}=w_{1} \ln C_{1, T}^{\text {Sat }}+w_{2} \ln C_{2, T}^{\text {Sat }}+w_{3} \ln C_{3, T}^{\text {Sat }} \\
& +\left[\frac{w_{1} w_{2}}{T} \sum_{i=0}^{2} J_{i}\left(w_{1}-w_{2}\right)^{i}\right]+\left[\frac{w_{1} w_{3}}{T} \sum_{i=0}^{2} J_{i}^{\prime}\left(w_{1}-w_{3}\right)^{i}\right] \\
& +\left[\frac{w_{2} w_{3}}{T} \sum_{i=0}^{2} J_{i}^{\prime \prime}\left(w_{2}-w_{3}\right)^{i}\right] \\
& +\left[\frac{w_{1} w_{2} w_{3}}{T} \sum_{i=0}^{2} J_{i}^{\prime \prime \prime}\left(w_{1}-w_{2}-w_{3}\right)^{i}\right]
\end{aligned}
$$

The $J_{i}^{\prime \prime \prime}$ terms are calculated employing solubility data in ternary solvent mixtures by regressing

$$
\begin{aligned}
& \left\{\ln C_{m, T}^{\mathrm{Sat}}-w_{1} \ln C_{1, T}^{\mathrm{Sat}}-w_{2} \ln C_{2, T}^{\mathrm{Sat}}-w_{3} \ln C_{3, T}^{\mathrm{Sat}}\right. \\
& -\left[\frac{w_{1} w_{2}}{T} \sum_{i=0}^{2} J_{i}\left(w_{1}-w_{2}\right)^{i}\right]-\left[\frac{w_{1} w_{3}}{T} \sum_{i=0}^{2} J_{i}^{\prime}\left(w_{1}-w_{3}\right)^{i}\right] \\
& \left.\quad-\left[\frac{w_{2} w_{3}}{T} \sum_{i=0}^{2} J_{i}^{\prime \prime}\left(w_{2}-w_{3}\right)^{i}\right]\right\}
\end{aligned}
$$

against $\left(w_{1} w_{2} w_{3}\right) / T,\left[w_{1} w_{2} w_{3}\left(w_{1}-w_{2}-w_{3}\right)\right] / T$, and $\left[w_{1} w_{2} w_{3}\left(w_{1}-w_{2}-w_{3}\right)^{2}\right] / T$. These constants represent the three-body solvent-solvent interaction terms between solvents 1 to 3 and the four-body interactions between the solute and solvents 1 to 3 .

It is possible to calculate the $J$ terms at one temperature and to predict the solubility of a solute at other temperatures. ${ }^{9}$ The prediction of the solubility in the mixed solvents at various temperatures with a trained Jouyban-Acree model needs a number of experimental solubility data points in the monosolvents, what can be considered as a limitation of this model.

To check the validity of the model for predicted solubility values, a comparison is made between calculated and experimental data by the mean percentage deviation (MPD)

$$
\mathrm{MPD}=\frac{100}{N} \sum\left(\frac{\left|C_{\text {calculated }}^{\text {Sat }}-C_{\text {experimental }}^{\text {Sat }}\right|}{C_{\text {experimental }}^{\text {Sat }}}\right)
$$

in which $N$ is the number of data points in each set.

\section{EXPERIMENTAL SECTION}

Materials. Sodium acetate (anhydrous form, mass fraction purity of 0.995 ), $\mathrm{MeOH}$ (mass fraction purity of 0.999 ), $\mathrm{PrOH}$ (mass fraction purity of 0.999 ), and ACN (mass fraction purity of 0.998 ) were purchased from Scharlau (Barcelona, Spain). Deionized water (Ghazi Pharmaceutical Co., Tabriz, Iran) was used for the preparation of the ternary mixtures and desired dilutions.

Solubility Measurements. According to the saturation shake-flask method of Higuchi and Connors ${ }^{13}$ for the solubility determination, a slight excess of sample powder was introduced into flasks containing the desired mass fraction of the ternary solvent mixtures. The solvent mixtures were prepared by mixing the appropriate amounts of the solvents. Suspensions were placed in a temperature-controlled bath (Behdad, Tehran, Iran) under constant shaking at 298.2 ( \pm 0.2) $\mathrm{K}$ until equilibrium was attained. After more than $72 \mathrm{~h}$ the solid 
Table 1. Experimental Molar Solubilities, $C_{m, T}^{\text {Sat }}$, of Sodium Acetate in the Investigated Ternary Solvent Mixtures at $298.2 \mathrm{~K}$ and Atmospheric Pressure, the Mole Fraction Solubility, Density of the Saturated Solutions, and Their Standard Deviation Values (SD) at Different Compositions (in Mass Fractions) of Solvents 1 to $3, w_{1}, w_{2}$, and $w_{3}$

\begin{tabular}{|c|c|c|c|c|c|c|c|}
\hline$w_{1}$ & $w_{2}$ & $w_{3}$ & $C_{m, T}^{\mathrm{Sat}} / \mathrm{mol} \cdot \mathrm{L}^{-1}$ & $\mathrm{SD}$ & $X_{m, T}^{\text {Sat }}$ & $\rho_{m, T}^{\mathrm{Sat}} / \mathrm{g} \cdot \mathrm{cm}^{-3}$ & $\mathrm{SD}$ \\
\hline \multicolumn{8}{|c|}{ Water (1) + MeOH (2) + PrOH (3) } \\
\hline 0.12 & 0.10 & 0.78 & 0.25 & $0.00^{a}$ & 0.0157 & 0.8432 & 0.0040 \\
\hline 0.12 & 0.39 & 0.49 & 1.66 & 0.04 & 0.0874 & 0.9010 & 0.0011 \\
\hline 0.12 & 0.48 & 0.39 & 1.69 & 0.06 & 0.0832 & 0.9100 & 0.0019 \\
\hline 0.12 & 0.78 & 0.10 & 1.96 & 0.04 & 0.0774 & 0.9357 & 0.0011 \\
\hline 0.24 & 0.38 & 0.38 & 1.40 & 0.06 & 0.0645 & 0.9087 & 0.0011 \\
\hline 0.35 & 0.28 & 0.37 & 1.45 & 0.06 & 0.0621 & 0.9428 & 0.0033 \\
\hline 0.35 & 0.37 & 0.28 & 1.56 & 0.04 & 0.0626 & 0.9428 & 0.0084 \\
\hline 0.38 & 0.31 & 0.31 & 1.73 & 0.04 & 0.0691 & 0.9640 & 0.0084 \\
\hline 0.45 & 0.09 & 0.46 & 1.94 & 0.08 & 0.0832 & 0.9820 & 0.0049 \\
\hline 0.46 & 0.18 & 0.37 & 1.96 & 0.07 & 0.0783 & 0.9891 & 0.0019 \\
\hline 0.46 & 0.27 & 0.27 & 2.02 & 0.07 & 0.0752 & 0.9936 & 0.0059 \\
\hline 0.46 & 0.36 & 0.18 & 2.24 & 0.09 & 0.0773 & 1.0071 & 0.0059 \\
\hline 0.46 & 0.45 & 0.09 & 2.64 & 0.10 & 0.0849 & 1.0180 & 0.0019 \\
\hline 0.56 & 0.09 & 0.36 & 2.47 & 0.10 & 0.0935 & 1.0238 & 0.0019 \\
\hline 0.56 & 0.35 & 0.09 & 3.17 & 0.12 & 0.0973 & 1.0456 & 0.0029 \\
\hline 0.84 & 0.08 & 0.08 & 3.58 & 0.10 & 0.0883 & 1.1324 & 0.0040 \\
\hline \multicolumn{8}{|c|}{ Water (1) + $\mathrm{MeOH}(2)+\mathrm{ACN}(3)$} \\
\hline 0.12 & 0.10 & 0.78 & 0.08 & 0.00 & 0.0036 & 0.8001 & 0.0019 \\
\hline 0.12 & 0.39 & 0.48 & 0.88 & 0.04 & 0.0368 & 0.8734 & 0.0019 \\
\hline 0.12 & 0.49 & 0.39 & 1.04 & 0.02 & 0.0418 & 0.8914 & 0.0011 \\
\hline 0.12 & 0.78 & 0.10 & 1.57 & 0.03 & 0.0576 & 0.9306 & 0.0012 \\
\hline 0.24 & 0.38 & 0.38 & 1.18 & 0.02 & 0.0448 & 0.9010 & 0.0011 \\
\hline 0.35 & 0.28 & 0.37 & 1.20 & 0.04 & 0.0427 & 0.9197 & 0.0051 \\
\hline 0.35 & 0.37 & 0.28 & 1.27 & 0.02 & 0.0424 & 0.9518 & 0.0029 \\
\hline 0.39 & 0.31 & 0.30 & 1.52 & 0.06 & 0.0515 & 0.9454 & 0.0029 \\
\hline 0.46 & 0.27 & 0.27 & 1.60 & 0.03 & 0.0499 & 0.9820 & 0.0013 \\
\hline 0.46 & 0.36 & 0.18 & 1.72 & 0.05 & 0.0518 & 0.9981 & 0.0011 \\
\hline 0.46 & 0.45 & 0.09 & 2.33 & 0.10 & 0.0692 & 1.0199 & 0.0019 \\
\hline 0.56 & 0.35 & 0.09 & 3.14 & 0.06 & 0.0903 & 1.0482 & 0.0044 \\
\hline 0.84 & 0.08 & 0.08 & 3.48 & 0.08 & 0.0794 & 1.1337 & 0.0033 \\
\hline \multicolumn{8}{|c|}{ Water $(1)+\operatorname{PrOH}(2)+\mathrm{ACN}(3)$} \\
\hline 0.12 & 0.78 & 0.10 & 0.10 & 0.00 & 0.0062 & 0.8136 & 0.0019 \\
\hline 0.12 & 0.49 & 0.38 & 0.05 & 0.00 & 0.0029 & 0.8040 & 0.0019 \\
\hline 0.12 & 0.40 & 0.48 & 0.05 & 0.00 & 0.0026 & 0.8091 & 0.0029 \\
\hline 0.12 & 0.10 & 0.78 & 0.02 & 0.00 & 0.0009 & 0.7943 & 0.0019 \\
\hline 0.24 & 0.39 & 0.37 & 0.24 & 0.00 & 0.0127 & 0.8342 & 0.0011 \\
\hline 0.35 & 0.28 & 0.37 & 0.26 & 0.00 & 0.0121 & 0.8271 & 0.0019 \\
\hline 0.38 & 0.31 & 0.31 & 0.27 & 0.00 & 0.0123 & 0.8368 & 0.0019 \\
\hline 0.46 & 0.46 & 0.09 & 1.13 & 0.03 & 0.0510 & 0.9119 & 0.0019 \\
\hline 0.84 & 0.08 & 0.08 & 3.32 & 0.07 & 0.0846 & 1.1144 & 0.0019 \\
\hline \multicolumn{8}{|c|}{$\mathrm{MeOH}(1)+\mathrm{PrOH}(2)+\mathrm{ACN}(3)$} \\
\hline 0.10 & 0.10 & 0.80 & 0.05 & 0.00 & 0.0025 & 0.7892 & 0.0011 \\
\hline 0.10 & 0.41 & 0.49 & 0.07 & 0.00 & 0.0044 & 0.7943 & 0.0019 \\
\hline 0.10 & 0.51 & 0.39 & 0.08 & 0.00 & 0.0047 & 0.7995 & 0.0011 \\
\hline 0.10 & 0.80 & 0.10 & 0.09 & 0.00 & 0.0061 & 0.8033 & 0.0011 \\
\hline 0.20 & 0.41 & 0.39 & 0.09 & 0.00 & 0.0055 & 0.7988 & 0.0011 \\
\hline 0.30 & 0.31 & 0.39 & 0.13 & 0.01 & 0.0075 & 0.7982 & 0.0019 \\
\hline 0.30 & 0.41 & 0.30 & 0.18 & 0.01 & 0.0104 & 0.8040 & 0.0019 \\
\hline 0.33 & 0.35 & 0.33 & 0.21 & 0.01 & 0.0115 & 0.8014 & 0.0011 \\
\hline 0.40 & 0.10 & 0.50 & 0.22 & 0.01 & 0.0108 & 0.7995 & 0.0011 \\
\hline 0.40 & 0.20 & 0.40 & 0.24 & 0.02 & 0.0124 & 0.8008 & 0.0011 \\
\hline 0.40 & 0.30 & 0.30 & 0.24 & 0.02 & 0.0131 & 0.8020 & 0.0019 \\
\hline 0.40 & 0.40 & 0.20 & 0.25 & 0.01 & 0.0140 & 0.8053 & 0.0011 \\
\hline 0.40 & 0.50 & 0.10 & 0.30 & 0.01 & 0.0175 & 0.8040 & 0.0019 \\
\hline 0.50 & 0.10 & 0.40 & 0.31 & 0.02 & 0.0152 & 0.7988 & 0.0011 \\
\hline 0.50 & 0.40 & 0.10 & 0.44 & 0.01 & 0.0248 & 0.8072 & 0.0011 \\
\hline 0.80 & 0.10 & 0.10 & 0.86 & 0.04 & 0.0390 & 0.8310 & 0.0019 \\
\hline
\end{tabular}


Table 1. continued

${ }^{a} 0.00$ means the value is less than 0.005 .

phase was removed by a centrifuge (Sanyo, UK) at $13000 \mathrm{rpm}$ for $10 \mathrm{~min}$, and the obtained clear solutions were filtered with a compatible membrane filter $(0.45 \mu \mathrm{m}$ pore size, Albet Lab Science, Spain). The clear solutions were diluted quantitatively with deionized water and assayed using a flame photometer (Fater Electronics, Tehran, Iran). The solubility determinations were done by a single point calibration curve with the adjustment by unsaturated solutions of sodium acetate of defined concentrations. The uncertainty of the measurements is mainly influenced by the error caused by the calibration of the flame photometer, which was performed before each measurement.

The densities of the solutions were measured using a balance and a $5 \mathrm{~mL}$ pycnometer at $298.2( \pm 0.2) \mathrm{K}$. The experimental densities were used to convert the molar solubilities into mole fraction solubilities. Note that all of the experimental solubility and density results are averages of measurements conducted in at least triplicate. The relative standard deviation (RSD\%) for the solubility and density measurements were $3.2 \%$ and $0.3 \%$, respectively.

\section{RESULTS AND DISCUSSION}

Solubility. Measured Data. The experimentally obtained solubility of sodium acetate in ternary solvent mixtures of water, $\mathrm{MeOH}, \mathrm{PrOH}$, and $\mathrm{ACN}$ at $298.2 \mathrm{~K}$, along with the experimental densities, are listed in Table 1. The solubilities for all systems are expressed on both the molar and the mole fraction scales, while the solvent composition is expressed as mass fraction on the salt-free basis. Also, the indeterminate errors expressed by the standard deviations are reported in the fifth and eighth columns of Table 1.

The pronounced property of water as solvator of the salt is clearly seen from the similar solubility of sodium acetate in the investigated ternary mixtures with approximately the same water content of about 0.8 , which is between $(3.3$ and 3.6$) \mathrm{mol}$. $\mathrm{L}^{-1}$, and is independent of the kinds of cosolvents. The maximum solubility was observed in the water $+\mathrm{MeOH}+$ ACN ternary system at mass fractions of $0.84 / 0.08 / 0.08$ with a value of $3.58 \mathrm{~mol} \cdot \mathrm{L}^{-1}$. For a comparison the molar solubility of sodium acetate in pure water is $5.53 \mathrm{~mol} \cdot \mathrm{L}^{-1}$, which is at least in the same order of magnitude.

The lowest solubility is found in the ACN-rich, water-free solvent mixture, with $\mathrm{MeOH} / \mathrm{PrOH} / \mathrm{ACN}$ mass fractions of $0.10,0.10$, and 0.80 , respectively. The observed solubility of sodium acetate in this ternary mixture corresponds to 0.046 $\mathrm{mol} \cdot \mathrm{L}^{-1}$. This value is about 2 orders of magnitude lower than the highest solubility found (see above) and differs by a factor of 50 from that observed in pure ACN $\left(0.0014 \mathrm{~mol} \cdot \mathrm{L}^{-1}\right)$ reported in an earlier work. ${ }^{7}$

Modeling of Solubility. As discussed in the Introduction section, one can construct a model for solubility predictions given that the experimental solubility data for sodium acetate in the monosolvents and their binary solvent mixtures are available. For this aim, the experimental solubility data points were described with the temperature-dependent eq 1 for the calculation of model constants as reported in an earlier work. ${ }^{7}$ After computation of the model constants (see Table 2), it is in principle possible to predict the solubility of sodium acetate in ternary mixtures of solvents 1,2 , and 3 at each mixture
Table 2. Numerical Values of the Model Constants of the Jouyban-Acree Model and Mean Percentage Deviation (MPD) for the Solubility of Sodium Acetate in Ternary Mixtures Using Equations 2 and 3

$\begin{array}{lcccccc}\text { solvent system } & N & J_{0}^{\prime \prime \prime} & J_{1}^{\prime \prime \prime} & J_{2}^{\prime \prime \prime} & \text { eq 2 } & \text { eq 3 } \\ \begin{array}{l}\text { water + MeOH + } \\ \text { PrOH }\end{array} & 16 & 9195 & 20668 & 35910 & 50.4 & 19.1 \\ \begin{array}{l}\text { water + MeOH + } \\ \text { ACN }\end{array} & 13 & 16575 & 40715 & 47467 & 61.4 & 12.5 \\ \begin{array}{c}\text { water + PrOH + } \\ \text { ACN }\end{array} & 9 & 20573 & 41900 & a & 80.4 & 36.7 \\ \begin{array}{l}\text { MeOH + PrOH + } \\ \text { ACN }\end{array} & 16 & 7075 & 16364 & a & 37.1 & 31.8 \\ \\ { }^{a} \text { Not statistically significant }(p>0.10) .\end{array}$

composition. The predicted solubility data were compared with those experimentally obtained (given in Table 1), and their deviations were expressed by the MPD values. The MPD values are given in the next to last column of Table 2. Examination of the numerical entries reveals the MPD values are between $37 \%$ and $80 \%$, with an OMPD value of around $57 \%$. The large deviations were not satisfactory so we introduced an additional term into the model to take into account the mutual effect of all three solvents in the ternary mixture as expressed by eq 3 . Consequently, the trained model for the prediction of sodium acetate solubility in ternary mixtures of water (1) $+\mathrm{MeOH}$ (2) $+\mathrm{PrOH}$ (3) taken as example is

$$
\begin{aligned}
\ln C_{m, T}^{\text {Sat }}= & w_{1} \ln C_{1, T}^{\text {Sat }}+w_{2} \ln C_{2, T}^{\text {Sat }}+w_{3} \ln C_{3, T}^{\text {Sat }} \\
& +\left[\frac{-142 w_{1} w_{2}}{T}-\frac{652 w_{1} w_{2}\left(w_{1}-w_{2}\right)}{T}\right. \\
& \left.-\frac{235 w_{1} w_{2}\left(w_{1}-w_{2}\right)^{2}}{T}\right] \\
& +\left[\frac{-233 w_{1} w_{3}}{T}-\frac{1008 w_{1} w_{3}\left(w_{1}-w_{3}\right)}{T}\right] \\
& +\left[\frac{277 w_{2} w_{3}}{T}+\frac{81 w_{2} w_{3}\left(w_{2}-w_{3}\right)}{T}\right. \\
& \left.-\frac{1581 w_{2} w_{3}\left(w_{2}-w_{3}\right)^{2}}{T}\right] \\
& +\left[\frac{9195 w_{1} w_{2} w_{3}}{T}\right. \\
& +\frac{20668 w_{1} w_{2} w_{3}\left(w_{1}-w_{2}-w_{3}\right)}{T} \\
& \left.+\frac{35910 w_{1} w_{2} w_{3}\left(w_{1}-w_{2}-w_{3}\right)^{2}}{T}\right]
\end{aligned}
$$

The model constants for the investigated binary and ternary solvent systems are summerized in Tables 2 and 3. Note that eq 5 will be reduced to the corresponding binary premixed solvent systems when either $w_{1}, w_{2}$, or $w_{3}$ is equal to zero. 
Table 3. Numerical Values of the Constants of the JouybanAcree Model Taken from a Previous Work ${ }^{7}$ for the Solubility of Sodium Acetate in Binary Solvent Mixtures

\begin{tabular}{clll} 
solvent system & $J_{0}$ & \multicolumn{1}{c}{$J_{1}$} & \multicolumn{1}{c}{$J_{2}$} \\
water $+\mathrm{MeOH}$ & -142 & -652 & -235 \\
water $+\mathrm{PrOH}$ & -233 & -1008 & $a$ \\
water $+\mathrm{ACN}$ & 1766 & -6291 & $a$ \\
$\mathrm{MeOH}+\mathrm{PrOH}$ & 277 & 81 & -1581 \\
$\mathrm{MeOH}+\mathrm{ACN}$ & 2344 & -1801 & -634 \\
$\mathrm{PrOH}+\mathrm{ACN}$ & 382 & $a$ & $a$ \\
${ }^{a}$ Not statistically significant $(p>0.10)$. & & \\
\hline
\end{tabular}

The accuracy of the data obtained from trained versions of eq 3 (see Table 3 for details) was evaluated by comparison of the predicted solubilities with the corresponding experimental data, and their deviation was expressed by the MPD values. It can be seen from Table 2 that the MPD values vary much less compared to the predictions without using ternary solvent interaction terms, namely, only between $12.5 \%$ and $36.7 \%$. The reason for larger MPD for eq 2 in comparison to eq 3 is that ternary solvent mixtures possess some additional interactions between the three solvents and the solute which have not been considered in eq 2 . However, the main advantage of eq 2 over eq 3 is that it could be used to predict the solute solubility in ternary solvent mixtures without employing any experimental solubility data in ternary solvent mixtures. It can be seen that the highest MPD value of $36.7 \%$ is found for the water $+\mathrm{PrOH}+\mathrm{ACN}$ mixture. As a major cause of the observed still high MPD value, the less number of data points of this mixture in ternary (with nine data points) and binary premixtures (water $+\mathrm{ACN}$, with seven data points) due to phase separation can be considered. It might be surprising that the lowest MPD value of $12.5 \%$ is not found for the ternary mixture of the protic solvents (water and the alcohols), but for that which contains the apolar diprotic solvent ACN.

Accordingly, the worst linear correlation between experimental and calculated solubilities, expressed by the linear correlation coefficient, $R$, is found in the mixtures of the polar solvent constituents of the ternary mixture, namely, with $R=$ 0.63 for water $/ \mathrm{MeOH} / \mathrm{PrOH}$, whereas the best value gives the mixture with the water-free solvent mixture $\mathrm{MeOH} / \mathrm{PrOH} /$ ACN with $R=0.97$. In Figure 1 , the solubility of sodium acetate in all ternary mixtures predicted by eq 3 is plotted versus its experimental amount. The linear correlation coefficient for all data is $R=0.92$, with a slope deviating from the ideal value of unity pointing to a slight underestimation of the calculated data from the experimental ones.

Density. The Jouyban-Acree model ${ }^{14}$ could be favorably used to predict the density of saturated solvent mixtures. The model for correlating density of binary and ternary solvents at various temperatures is

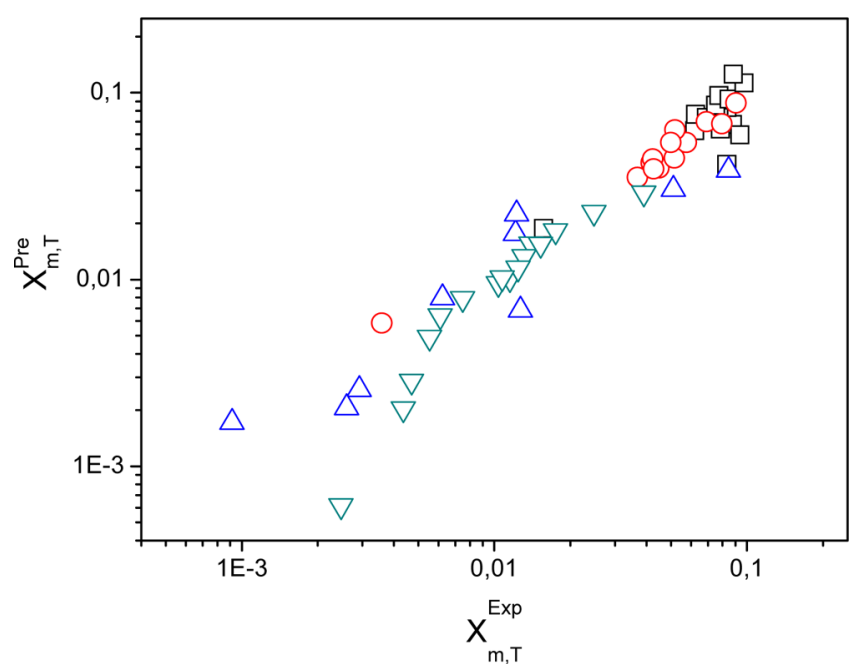

Figure 1. Predicted mole fraction solubility $\left(X_{m, T}{ }^{\mathrm{Pre}}\right)$ of sodium acetate versus experimental $\left(X_{m, T}{ }^{\text {Exp }}\right)$ values for the following mixed solvents: $\square$, water (1) $+\mathrm{MeOH}(2)+\mathrm{PrOH}(3)$; red O, water (1) $+\mathrm{MeOH}$ (2) + ACN (3); blue $\triangle$, water (1) + PrOH (2) + ACN (3); green $\nabla$, $\mathrm{MeOH}(1)+\mathrm{PrOH}(2)+\mathrm{ACN}(3)$.

$$
\begin{aligned}
\ln \rho_{m, T}^{\text {Sat }}= & w_{1} \ln \rho_{1, T}^{\text {Sat }}+w_{2} \ln \rho_{2, T}^{\text {Sat }}+w_{3} \ln \rho_{3, T}^{\text {Sat }} \\
& +\frac{w_{1} w_{2}}{T} \sum_{i=0}^{2} A_{i}^{\prime}\left(w_{1}-w_{2}\right)^{i}+\frac{w_{1} w_{3}}{T} \\
& \sum_{i=0}^{2} A_{i}^{\prime \prime}\left(w_{1}-w_{3}\right)^{i}+\frac{w_{2} w_{3}}{T} \sum_{i=0}^{2} A_{i}^{\prime \prime \prime}\left(w_{2}-w_{3}\right)^{i} \\
& +\left[\frac{w_{1} w_{2} w_{3}}{T} \sum_{i=0}^{2} A_{i}^{\prime \prime \prime \prime}\left(w_{1}-w_{2}-w_{3}\right)^{i}\right]
\end{aligned}
$$

where $\rho_{m, T}^{\mathrm{Sat}}, \rho_{1, T}^{\mathrm{Sat}}, \rho_{2, T}^{\mathrm{Sat}}$, and $\rho_{3, T}^{\mathrm{Sat}}$ are the densities of the saturated solution in the mixture and in solvents 1,2 , and 3 at the temperature $T$, respectively, $A_{i}^{\prime}$ to $A_{i}^{\prime \prime \prime \prime}$ are the model constants. The numerical values of $A_{i}$ to $A_{i}^{\prime \prime \prime}$ terms could be calculated using a regression analysis similar to that of the explained procedure for the solubility data.

In Table 1 the experimentally obtained densities of the saturated solutions of sodium acetate in the ternary solvent mixtures are given. The range of experimental densities is much smaller than that of the solubilities: the densities are between about $(0.8$ and 1.1$) \mathrm{g} \cdot \mathrm{cm}^{-3}$. It is also self-explanatory that the density data for the particular mixture is more reproducible compared to the solubility data due to the higher precision of the measurement with a pycnometer compared to a flame photometer. Indeed the relative standard deviation of the density is below $1 \%$ for all measurements.

Table 4 lists the numerical values of $A_{i}$ terms for the investigated ternary solvent systems. The binary $A_{i}$ values for binary solvent interaction terms are adopted from the previously published paper. ${ }^{7}$ By employing the model constants listed in Table 4 and the density of the saturated solutions in the monosolvents at $T$, i.e., $\rho_{1, T}^{\text {Sat }}, \rho_{2, T}^{\text {Sat }}$, and $\rho_{3, T}^{\text {Sat }}$, the density of solute saturated solutions in ternary solvent mixtures could be predicted. The MPD values for this analysis are also given in Table 4: the overall MPD value of the density data was $1.2 \%$. Also, the density of ternary solvent mixtures could be predicted by using only the binary constants with an error of $3.0 \%$. In another analysis, the densities of the solute-saturated ternary 
Table 4. Numerical Values of the Model Constants of the Jouyban-Acree Model and Mean Percentage Deviation (MPD) for Modeling the Density of Sodium Acetate in Ternary Solvent Mixture

\begin{tabular}{|c|c|c|c|c|c|c|}
\hline \multirow[b]{2}{*}{ solvent system } & \multirow[b]{2}{*}{$N$} & \multirow[b]{2}{*}{$A_{0}^{\prime \prime \prime \prime}$} & \multirow[b]{2}{*}{$A_{1}^{\prime \prime \prime \prime}$} & \multicolumn{3}{|c|}{ MPD\% } \\
\hline & & & & I & III & III \\
\hline water $+\mathrm{MeOH}+\mathrm{PrOH}$ & 16 & -565 & -702 & 1.1 & 3.6 & 2.0 \\
\hline water $+\mathrm{MeOH}+\mathrm{ACN}$ & 13 & -346 & -1370 & 1.7 & 2.6 & 1.9 \\
\hline water $+\mathrm{PrOH}+\mathrm{ACN}$ & 9 & -841 & -2210 & 1.1 & 3.9 & 5.9 \\
\hline $\mathrm{MeOH}+\mathrm{PrOH}+\mathrm{ACN}$ & 16 & 218 & $a$ & 0.9 & 2.0 & 1.6 \\
\hline & & & & 1.2 & 3.0 & 2.8 \\
\hline
\end{tabular}

${ }^{a}$ Not statistically significant $(p>0.10)$. I, II, and III: Prediction errors of the saturated density of the ternary mixtures using ternary, binary, and solute free binary constants, respectively.

solvent mixtures are predicted by using binary solute free densities with an overall MPD of $2.8 \%$. Table 5 shows the $A_{i}$

Table 5. Numerical Values of the Model Constants of the Jouyban-Acree Model for Calculating Density Data Using Solute-Free Data in the Binary Solvent Mixtures of the Investigated Ternary Solvent Mixtures

\begin{tabular}{clllll} 
solvent system & $A_{0}^{\prime}$ & \multicolumn{1}{c}{$A_{1}^{\prime}$} & $A_{2}^{\prime}$ & $N$ & MPD \\
water $+\mathrm{MeOH}$ & 34 & -10 & -5 & 13 & $<0.1$ \\
water $+\mathrm{PrOH}$ & 16 & 6 & 9 & 15 & $<0.1$ \\
$\mathrm{PrOH}+\mathrm{MeOH}$ & -1 & -0.6 & 0.9 & 27 & $<0.1$ \\
$\mathrm{MeOH}+\mathrm{ACN}$ & 3 & 2 & 0.7 & 14 & $<0.1$ \\
water $+\mathrm{ACN}$ & 15 & 12 & 6 & 15 & $<0.1$ \\
$\mathrm{PrOH}+\mathrm{ACN}$ & $a$ & $a$ & $a$ & 11 & 0.2 \\
& & & overall & & approx. 0.3
\end{tabular}

values of binary solute free solvent mixtures that are collected from the literature. ${ }^{15-19}$ Figure 2 compares the experimental density of sodium acetate in ternary mixtures and predicted values based on eq 6 . The squared correlation coefficient of $R^{2}$

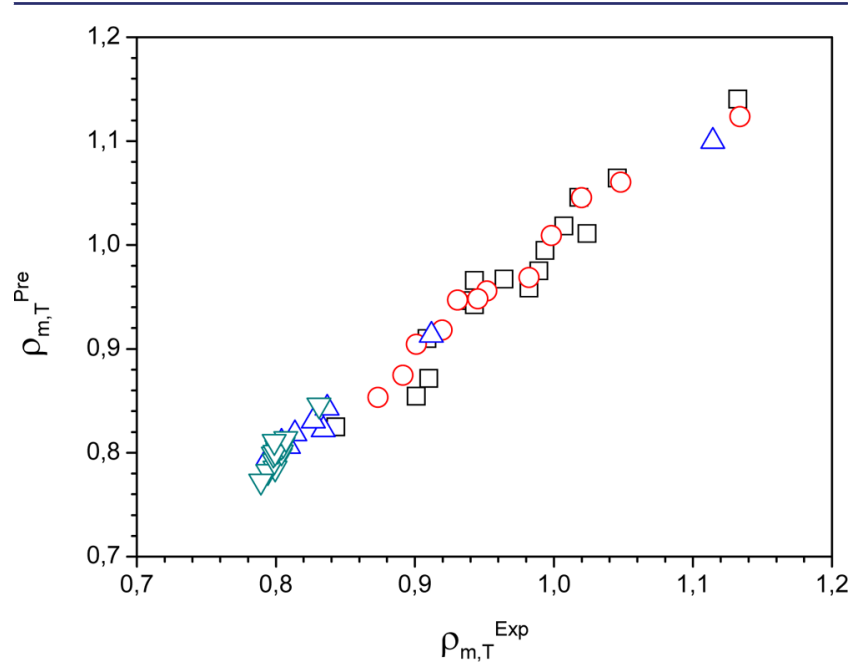

Figure 2. Predicted density of sodium acetate $\left(\rho_{m, T}^{\mathrm{Pre}}\right)$ versus experimental $\left(\rho_{m, T}^{\text {Exp }}\right)$ values for the following mixed solvents: $\square$, water (1) + $\mathrm{MeOH}(2)+\mathrm{PrOH}(3)$; red O, water (1) $+\mathrm{MeOH}(2)+$ $\operatorname{ACN}(3)$; blue $\triangle$, water (1) $+\operatorname{PrOH}(2)+\operatorname{ACN}(3)$; green $\nabla$, $\mathrm{MeOH}(1)+\mathrm{PrOH}(2)+\mathrm{ACN}(3)$.
$=0.98$ indicates good agreement between the calculated and the experimental values.

\section{CONCLUSIONS}

The solubilities of sodium acetate in aqueous and nonaqueous ternary mixtures of water $+\mathrm{MeOH}+\mathrm{PrOH}$, water $+\mathrm{MeOH}+$ $\mathrm{ACN}$, water $+\mathrm{PrOH}+\mathrm{ACN}$, and $\mathrm{MeOH}+\mathrm{PrOH}+\mathrm{ACN}$ are reported at $298.2 \mathrm{~K}$ along with their densities. The highest and the lowest solubilities were in ternary mixtures of water + $\mathrm{MeOH}+\mathrm{ACN}$ and $\mathrm{MeOH}+\mathrm{PrOH}+\mathrm{ACN}$ with mass fractions of $0.84 / 0.08 / 0.08$ and $0.10 / 0.10 / 0.80$, respectively. The observed solubility data are correlated with the JouybanAcree model. The addition of ternary interaction terms significantly improves the predictability of the Jouyban-Acree model as reflected by a reduction in the OMPD values by a factor of 2.

Density data of the saturated solutions are required in various applications and also to convert mole fraction solubility to molar or vice versa. As shown in this work, densities of the saturated solutions of ternary solvents could be predicted with an acceptable prediction error using mathematical expressions based on the Jouyban-Acree model and the experimental densities of the saturated solutions of sodium acetate dissolved in the monosolvents. These types of computations facilitate the required computations in process design investigations in the industries and/or academia.

\section{AUTHOR INFORMATION}

\section{Corresponding Author}

*E-mail: ajouyban@hotmail.com and jouyban@ut.ac.ir. Fax: +984113363231.

\section{Notes}

The authors declare no competing financial interest.

\section{REFERENCES}

(1) Long, B.; Zhao, D.; Liu, W. Thermodynamics Studies on the Solubility of Inorganic Salt in Organic Solvents: Application to KI in Organic Solvents and Water-Ethanol Mixtures. Ind. Eng. Chem. Res. 2012, 51, 9456-9467.

(2) Li, M.; Constantinescu, D.; Wang, L.; Mohs, A.; Gmehling, J. Solubilities of $\mathrm{NaCl}, \mathrm{KCl}, \mathrm{LiCl}$, and $\mathrm{LiBr}$ in Methanol, Ethanol, Acetone, and Mixed Solvents and Correlation Using the LIQUAC Model. Ind. Eng. Chem. Res. 2010, 49, 4981-4988.

(3) Food and Agriculture Organization of the United Nations. http://www.fao.org/ (accessed 2014).

(4) Application as buffer in pad-dry-cure technique: Fluorinated Surfactants and Repellents. http://textile-chemicals.net/products/ sodium-acetate/ (accessed 2001).

(5) McCague, A.; Dermendjieva, M.; Hutchinson, R.; Wong, D. T.; Dao, N. Sodium Acetate Infusion in Critically Ill Trauma Patients for Hyper Chloremicacidosis. Scand. J. Trauma. Resusc. Emerg. Med. 2011, $19,24$.

(6) Suarez, J. I.; Qureshi, A. I.; Parekh, P. D.; Razumovsky, A.; Tamargo, R. J.; Bhardwaj, A.; Ulatowski, J. A.; Neuro, J. Administration of Hypertonic (3\%) Sodium Chloride/Acetate in Hyponatremic Patients with Symptomatic Vasospasm Following Subarachnoid Hemorrhage. Anesthesiology 1999, 11, 178-184.

(7) Soleymani, J.; Zamani-Kalajahi, M.; Ghasemi, B.; Kenndler, E.; Jouyban, A. Solubility of Sodium Acetate in Binary Mixtures of Methanol, 1-Propanol, Acetonitrile, and Water at 298.2 K. J. Chem. Eng. Data 2013, 58, 3399-3404.

(8) Jouyban, A. Review of the Cosolvency Models for Predicting Solubility of Drugs in Water-Cosolvent Mixtures. J. Pharm. Pharmaceut. Sci. 2008, 11, 32-58. 
(9) Jouyban-Gharamaleki, A.; Acree, W. E., Jr. Comparison of models for describing multiple peaks in solubility profiles. Int. J. Pharm. 1998, $167,177-182$.

(10) Acree, W. E., Jr. Mathematical Representation of Thermodynamic Properties. Part II. Derivation of the Combined Nearly Ideal Binary Solvent (NIBS)/Redlich-Kister Mathematical Representation from a Two-Body and Three-Body Interactional Mixing Model. Thermochim. Acta 1992, 198, 71-79.

(11) Hwang, C. A.; Hostle, J. C.; Hall, K. R.; Mansoori, G. A. A Simple Relation to Predict or to Correlate the Excess Functions of Multicomponent Mixtures. Fluid Phase Equilib. 1991, 62, 173-189.

(12) Jouyban, A.; Acree, W. E., Jr. Comments on "Solubility of Ethyl Maltol in Aqueous Ethanol Mixtures”. J. Chem. Eng. Data 2009, 54, $1168-1170$.

(13) Higuchi, T.; Connors, K. A. Phase Solubility Diagram. Adv. Anal. Chem. Instrum. 1965, 4, 117-212.

(14) Jouyban, A.; Fathi-Azarbayjani, A.; Khoubnasabjafari, M.; Acree, W. E. Mathematical Representation of the Density of Liquid Mixtures at Various Temperatures using Jouyban-Acree model. Indian J. Chem. 2005, 44, 1553-1560.

(15) Iglesias, M.; Orge, B.; Tojo, J. Densities and Refractive Indices for Acetone + Methanol + 1-Propanol at 298.15 K. J. Chem. Eng. Data 1996, 41, 218-221.

(16) Nikam, P. S.; Shirsat, L. N.; Hasan, M. Density and Viscosity Studies of Binary Mixtures of Acetonitrile with Methanol, Ethanol, Propan-1-ol, Propan-2-ol, Butan-1-ol, 2-Methylpropan-1-ol, and 2Methylpropan-2-ol at $(298.15,303.15,308.15$, and 313.15) K. J. Chem. Eng. Data 1998, 43, 732-737.

(17) Hickey, K.; Waghorne, W. E. Viscosities and Volumes of Dilute Solutions of Formamide in Water - Acetonitrile and for Formamide and N,N-Dimethylformamide in Methanol-Acetonitrile Mixed Solvents: Viscosity B-Coefficients, Activation Free Energies for Viscous Flow, and Partial Molar Volumes. J. Chem. Eng. Data 2001, 46, 851857.

(18) Pang, F. M.; Seng, C. E.; Teng, T. T.; Ibrahim, M. H. Densities and Viscosities of Aqueous Solutions of 1-Propanol and 2-Propanol at Temperatures from 293.15 to 333.15 K. J. Mol. Liq. 2007, 136, 71-78.

(19) Gonzalez, B.; Calvar, N.; Gomez, E.; Domınguez, A. Density, Dynamic Viscosity, and Derived Properties of Binary Mixtures of Methanol or Ethanol with Water, Ethylacetate, and Methyl Acetate at $\mathrm{T}=(293.15,298.15$, and 303.15) K. J. Chem. Thermodyn. 2007, 39, $1578-1588$. 